\title{
KYLIN-V2.0 Code Calculation Ability Verification Based on VERA Benchmark
}

\author{
Dongyong Wang1,2, Yingrui Yu ${ }^{1,2}$, Xingjie Peng ${ }^{1,2^{*}}$, Chenlin Wang ${ }^{1,2}$, Kun Liu ${ }^{1,2}$, Xiaoming \\ Chai ${ }^{1,2}$
}

\section{Science and Technology on Reactor System Design Technology Laboratory, Chengdu, 610213, China}

\section{Nuclear Power Institute of China, Chengdu, 610213, China}

First author: wangdongyong717@163.com

Corresponding author: pengxingjiets@126.com

\begin{abstract}
Virtual Environmental for Reactor Analysis (VERA) benchmark was released by the Consortium for Advanced Simulation of Light water reactors (CASL) project in 2012. VERA benchmark includes more than ten problems at different levels, from 2D fuel pin case to 2D fuel assembly case to 3D core refuelling case, in addition, reference results and experimental measured data of some problems were provided by CASL. Fuel assemblies in VERA benchmark are various, including control rod assemblies, Pyrex assembly, IFBA assembly, WABA assembly and gadolinium poison assembly, and so on. In this paper, various fuel assembly models in the VERA benchmark have been built by using KYIIN-V2.0 code to verify its calculation ability from 2D fuel pin case to 2D fuel assembly case to 2D $3 \times 3$ fuel assembly case, and making a comparative analysis on the reference results in VERA benchmark, as well as the calculation results of the Monte Carlo code RMC. KYLIN-V2.0 is an advanced neutron transport lattice code developed by Nuclear Power Institute of China (NPIC). The subgroup resonance calculation method is used in KYIIN-V2.0 to obtain effective resonance selfshielding cross section, method of modular characteristics (MOC) is adopted to solve the neutron transport equation, and CRAM method and PPC method is adopted to solve the depletion equation. The numerical results show that KYLIN-V2.0 code has the reliable capability of direct heterogeneous calculation of 2D fuel assembly, and the effective multiplication factor, assembly power distribution, rod power distribution and control rod reactivity worths of various fuel assemblies that are calculated by KYLIN-V2.0 are in better agreement with the reference.
\end{abstract}

KEYWORDS: VERA, KYLIN-V2.0, effective multiplication factor, pin power, control rod reactivity worth

\section{INTRODUCTION}

In order to simulate the various fuel assemblies with complex structure geometry, and to meet the requirement of design and development, Nuclear Power Institute of China (NPIC) has developed an advanced neutron transport lattice code, named KYLIN-V2.0 [1,2]. It can provide two-dimensional few- 
group assembly-homogenized constants for the three-dimensional whole-core steady-state evaluation code named CORCA-3D[3], also developed by the NPIC.

The main flowchart of the KYLIN-V2.0 code is shown in Figure 1. The subgroup resonance calculation method is employed in KYLIN-V2.0 to obtain effective resonance self-shielding cross section, and to eliminate the limitations in lattice geometry and to guarantee both accuracy and efficiency, with multi-group energy structure in cross sections database. When more than one resonant nuclide exist, the Bondarenko iteration method is employed to treat the resonance interference effect. Method of modular characteristics (MOC) is adopted to solve the two-dimensional steady-state multi-group neutron transport equation. What's more, the MOC solver can be accelerated by using the Generalized Coarse Mesh Finite Differential (GCMFD) [4] scheme. The Chebyshev Rational Approximation Method (CRAM) [5] and the ProjectedPredictor-Corrector method (PPC) [6] is adopted to solve the depletion equation accurately and efficiently. In addition, the graphical input and display interface are developed to make sure the KYLIN-V2.0 code can be used easily by engineers.

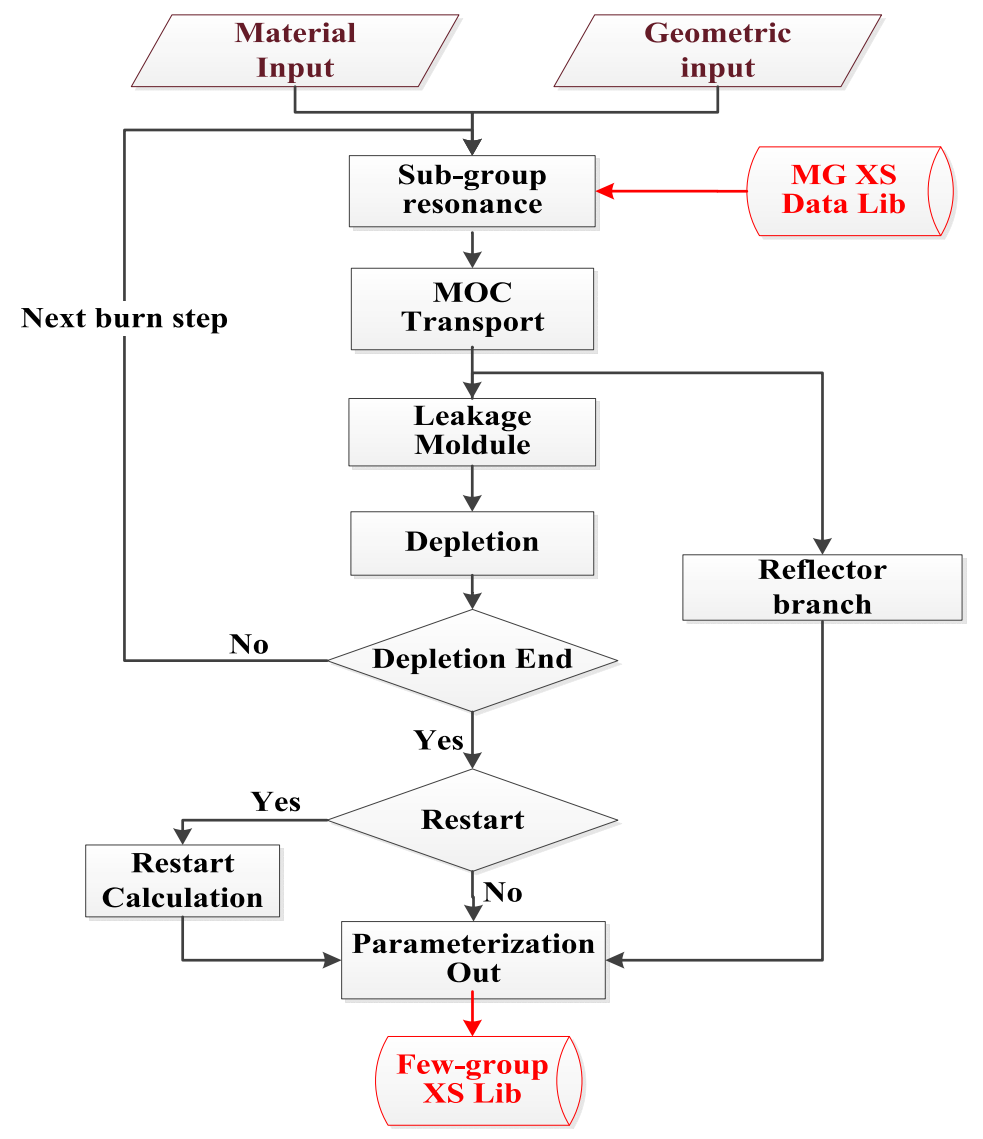

Figure 1. Main flowchart of KYLIN-V2.0.

The goal of this paper is to verify the calculation ability of the KYLIN-V2.0 code for various fuel assemblies. Therefore, 2D fuel pin models, 2D fuel assembly models, 2D 3x3 fuel assembly models in the VERA [7] benchmark will be built by using the KYLIN-V2.0 code. Physical quantities, calculated by the KYLINV2.0 code, such as the effective multiplication factor, assembly power maps, pin power maps and control rod reactivity worths were then compared to the reference results in VERA benchmark, as well as the calculation results of the Monte Carlo code RMC [8]. The verification of the KYLIN-V2.0 consists of two parts in this paper. The first part is about the no burnup problem, another is the burnup problem. 


\section{VERA BENCHMARK}

In the 21st century, Oak Ridge National Laboratory (ORNL) and dozens of institutions including the University of Michigan, MIT and Idaho National Laboratories (INL) have established the Consortium for Advanced Simulation of Light water reactors (CASL) project. The project is organized by the U.S. Department of Energy and is specifically managed by Oak Ridge National Laboratory. In addition, the VERA benchmark was released by the CASL group in 2012, and it includes more than ten problems at different levels. In this paper, 2D HZP BOC Pin Cell Problem, 2D HZP BOC Fuel Lattice Problem, and 2D HZP BOC $3 \times 3$ Assembly Problem in the VERA benchmark, their models will be built by using the KYLINV2.0 code to verify the code calculation capabilities.

\subsection{D HZP BOC Pin Cell Problem}

This problem consists of five calculation cases. Case 1A, 1B, 1C and 1D are all common fuel cell problem, Figure 2 shows a description of geometric of the common fuel cell at VERA benchmark. Each pin-cell is heterogeneous consisting of fuel pellet, gas-gap, cladding and moderator. Case 1E is an Integral Fuel Burnable Absorber (IFBA) fuel cell problem, it is a very thin (10um) ZrB2 coating on selected UO2 fuel pellets in an assembly [7].

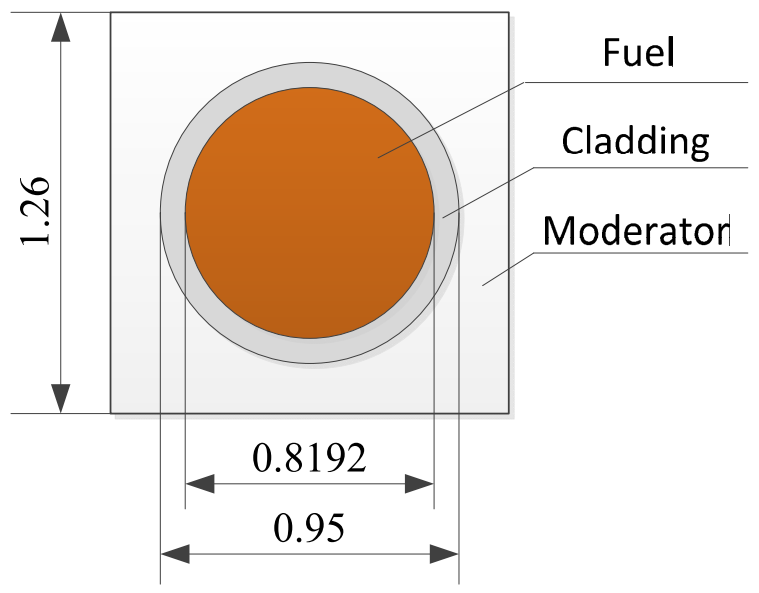

Figure 2. Common fuel cell geometry.

\subsection{D HZP BOC Fuel Lattice Problem}

This problem consists of various fuel assembly calculation cases, including silver-indium-cadmium (AIC) control rod assemblies, boron carbide (B4C) control rod assemblies, Pyrex (borosilicate glass, B2O3-SiO2) assembly, IFBA (Integral Fuel Burnable Absorber) assembly, WABA (Wet Annular Burnable Absorber) assembly and gadolinium poison assembly, and so on. The specifications of various fuel assemblies for this problem is provided in Table I. The fuel lattice of this problem is single Westinghouse 17x17-type, each assembly is comprised of 264 fuel rods, 24 guide tubes and 1 instrument tubes. The center distance of fuel lattice is $21.50 \mathrm{~cm}$, the half width of the water gap around the assembly is $0.04 \mathrm{~cm}$. Figure 3 shows the lattice layouts of problem $2 \mathrm{~N}$ at VERA benchmark, this calculation case consists of 104 IFBA and 20 WABA. 
Table I. Problem 2A-2P calculation cases.

\begin{tabular}{|c|c|c|c|c|}
\hline Case & Description & $\begin{array}{c}\text { Fuel } \\
\text { Temperature }\end{array}$ & $\begin{array}{c}\text { Moderator } \\
\text { Temperature }\end{array}$ & $\begin{array}{c}\text { Moderator } \\
\text { Density }\end{array}$ \\
\hline $2 \mathrm{~A}$ & No Poisons & $565 \mathrm{~K}$ & $565 \mathrm{~K}$ & $0.743 \mathrm{~g} / \mathrm{cm}^{-3}$ \\
\hline $2 \mathrm{~B}$ & No Poisons & $600 \mathrm{~K}$ & $600 \mathrm{~K}$ & $0.661 \mathrm{~g} / \mathrm{cm}^{-3}$ \\
\hline $2 \mathrm{C}$ & No Poisons & $900 \mathrm{~K}$ & $600 \mathrm{~K}$ & $0.661 \mathrm{~g} / \mathrm{cm}^{-3}$ \\
\hline $2 \mathrm{D}$ & No Poisons & $1200 \mathrm{~K}$ & $600 \mathrm{~K}$ & $0.661 \mathrm{~g} / \mathrm{cm}^{-3}$ \\
\hline $2 \mathrm{E}$ & 12 Pyrex & $600 \mathrm{~K}$ & $600 \mathrm{~K}$ & $0.743 \mathrm{~g} / \mathrm{cm}^{-3}$ \\
\hline $2 \mathrm{~F}$ & 24 Pyrex & $600 \mathrm{~K}$ & $600 \mathrm{~K}$ & $0.743 \mathrm{~g} / \mathrm{cm}^{-3}$ \\
\hline $2 \mathrm{G}$ & $24 \mathrm{AIC}$ & $600 \mathrm{~K}$ & $600 \mathrm{~K}$ & $0.743 \mathrm{~g} / \mathrm{cm}^{-3}$ \\
\hline $2 \mathrm{H}$ & $24 \mathrm{~B} 4 \mathrm{C}$ & $600 \mathrm{~K}$ & $600 \mathrm{~K}$ & $0.743 \mathrm{~g} / \mathrm{cm}^{-3}$ \\
\hline $2 \mathrm{I}$ & Instrument Thimble & $600 \mathrm{~K}$ & $600 \mathrm{~K}$ & $0.743 \mathrm{~g} / \mathrm{cm}^{-3}$ \\
\hline $2 \mathrm{~J}$ & Instrument +24 Pyrex & $600 \mathrm{~K}$ & $600 \mathrm{~K}$ & $0.743 \mathrm{~g} / \mathrm{cm}^{-3}$ \\
\hline $2 \mathrm{~K}$ & Zoned +24 Pyrex & $600 \mathrm{~K}$ & $600 \mathrm{~K}$ & $0.743 \mathrm{~g} / \mathrm{cm}^{-3}$ \\
\hline $2 \mathrm{~L}$ & 80 IFBA & $600 \mathrm{~K}$ & $600 \mathrm{~K}$ & $0.743 \mathrm{~g} / \mathrm{cm}^{-3}$ \\
\hline $2 \mathrm{M}$ & 128 IFBA & $600 \mathrm{~K}$ & $600 \mathrm{~K}$ & $0.743 \mathrm{~g} / \mathrm{cm}^{-3}$ \\
\hline $2 \mathrm{~N}$ & $104 \mathrm{IFBA}+20 \mathrm{WABA}$ & $600 \mathrm{~K}$ & $600 \mathrm{~K}$ & $0.743 \mathrm{~g} / \mathrm{cm}^{-3}$ \\
\hline 20 & 12 Gadolinia & $600 \mathrm{~K}$ & $600 \mathrm{~K}$ & $0.743 \mathrm{~g} / \mathrm{cm}^{-3}$ \\
\hline $2 \mathrm{P}$ & 24 Gadolinia & $600 \mathrm{~K}$ & $600 \mathrm{~K}$ & $0.743 \mathrm{~g} / \mathrm{cm}^{-3}$ \\
\hline
\end{tabular}

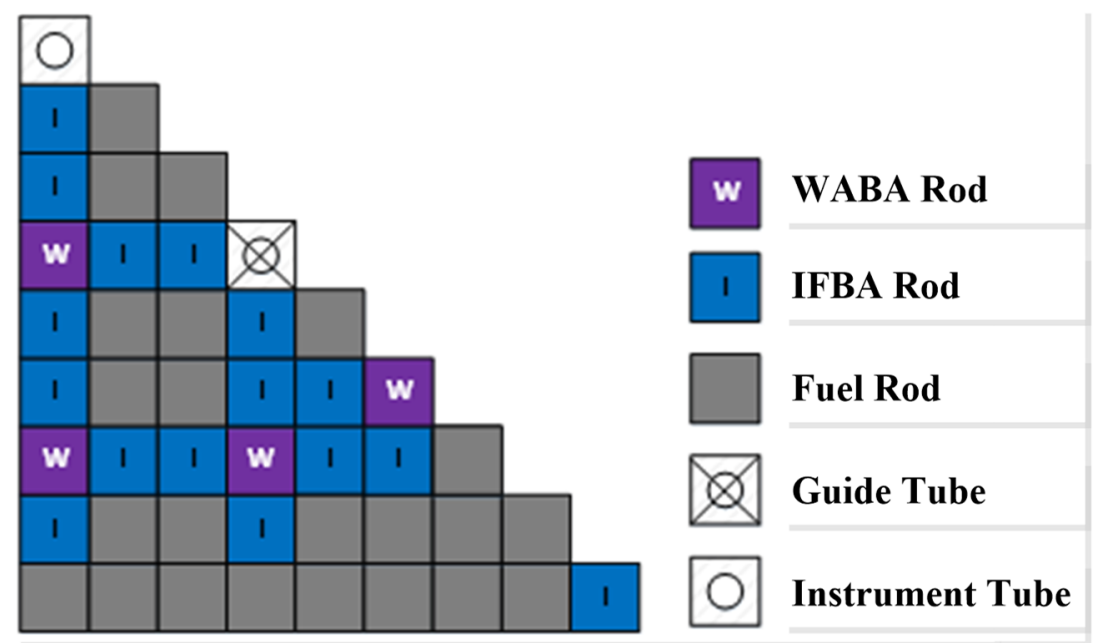

Figure 3. Problem 2N lattice layouts (Octant Symmetry).

\subsection{D HZP BOC 3x3 Assembly Problem}

This problem consists of nine 17x17-type fuel assemblies arranged in a $3 \times 3$ checkerboard pattern directly from the center of the WBN1 initial loading pattern, and it has three calculation cases in this problem, including uncontrolled (4A-2D), AIC (4B-2D), and $\mathrm{B}_{4} \mathrm{C}$ (4C-2D) controlled cases. Figure 4 shows the loading pattern of this problem at VERA benchmark. The main difference between the three calculation cases is whether the fuel assembly with $2.11 \%$ enrichment in the center contains control rods or not. This problem is mainly used to analyze the energy spectrum interference effect of fuel assembly and the 
influence of control rod. In addition, this problem also tests the ability to define and place Pyrex, AIC, and $\mathrm{B}_{4} \mathrm{C}$ absorbers in the assembly guide tubes. The moderator temperature is $600 \mathrm{~K}$, the moderator density is $0.743 \mathrm{~g} / \mathrm{cm} 3$ and the soluble boron concentration is $1300 \mathrm{ppm}$ in this problem.
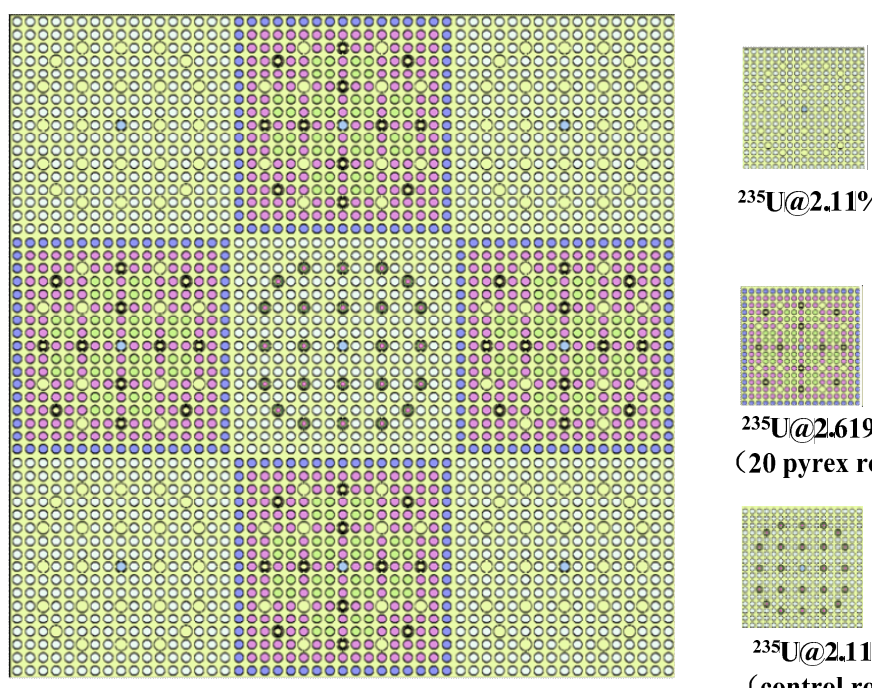

235U@2.11\%

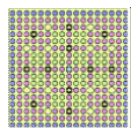

${ }^{235} \mathrm{U} @ 2.619 \%$

(20 pyrex rod)

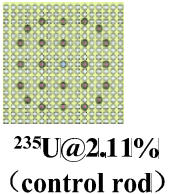

Figure 4. Problem 4-2D lattice layouts.

\section{NUMERICAL VERIFICATIONS}

\subsection{D pin cell calculation}

The VERA 2D UO $\mathrm{U}_{2}$ fuel pin-cell problem is calculated by using KYLIN-V2.0. The effective multiplication factor is been compared with the reference results calculated by KENO-VI code from VERA benchmark. Table II lists the reference values from the benchmark specification and the calculation values calculated by KINLY-V2.0. It can be found that KYLIN-V2.0 agrees well with the reference results from KENO-VI, the errors of the five calculation cases are all within $150 \mathrm{pcm}$.

Table II. Comparison of effective multiplication factor for 2D pin-cell problem.

\begin{tabular}{|c|c|c|c|c|c|c|c|}
\hline Case & Description & $\begin{array}{c}\text { Fuel } \\
\text { Temperature }\end{array}$ & $\begin{array}{c}\text { Moderator } \\
\text { Temperature }\end{array}$ & $\begin{array}{c}\text { Moderator } \\
\text { Density }\end{array}$ & KENO-VI & KYLIN-V2.0 & $\begin{array}{c}\text { ERROR } \\
/ \mathrm{pcm}\end{array}$ \\
\hline 1A & None & $565 \mathrm{~K}$ & $565 \mathrm{~K}$ & $0.743 \mathrm{~g} / \mathrm{cm}-3$ & 1.18704 & 1.18817 & 113 \\
\hline 1B & None & $600 \mathrm{~K}$ & $600 \mathrm{~K}$ & $0.661 \mathrm{~g} / \mathrm{cm}-3$ & 1.18215 & 1.18351 & 137 \\
\hline 1C & None & $900 \mathrm{~K}$ & $600 \mathrm{~K}$ & $0.661 \mathrm{~g} / \mathrm{cm}-3$ & 1.17172 & 1.17277 & 105 \\
\hline 1D & None & $1200 \mathrm{~K}$ & $600 \mathrm{~K}$ & $0.661 \mathrm{~g} / \mathrm{cm}-3$ & 1.16260 & 1.16356 & 96 \\
\hline 1E & IFBA & $600 \mathrm{~K}$ & $600 \mathrm{~K}$ & $0.743 \mathrm{~g} / \mathrm{cm}-3$ & 0.77169 & 0.77334 & 148 \\
\hline
\end{tabular}

\subsection{D single assembly calculation}

A comparison of the effective multiplication factor for KYLIN-V2.0 vs. KENO-VI for the 2D lattices comprising the VERA benchmark is given in Table III. The leftmost column indicates the name for each fuel lattice, while the "Description" column contains a succinct description of the lattice configuration. The 
table then shows the k-effective value obtained from KYLIN-V2.0 calculations and the difference between KYLIN-V2.0 and the reference results calculated by KENO-VI. When KENO-VI was calculating this problem, 1.1e9 particles are used, using 1100 generations with $1 \mathrm{e} 6$ particles per generation, skipping 100 generations. This resulted in a k-effective uncertainty of less than $3 \mathrm{pcm}$. It shows that it is accurate and reliable as a reference solution. The results from the Table III show excellent k-effective value agreement for KYLIN-V2.0 vs. CE KENO-VI across all lattices, with a max difference of $262 \mathrm{pcm}$.

Table III. Comparison of effective multiplication factor for 2D HZP fuel lattice problem.

\begin{tabular}{|c|c|c|c|c|}
\hline Case & Description & KENO-VI & KYLIN-V2.0 & ERROR /pcm \\
\hline 2A & No Poisons & $1.18218 \pm 0.000017$ & 1.18277 & 109 \\
\hline 2B & No Poisons & $1.18336 \pm 0.000024$ & 1.18417 & 131 \\
\hline 2C & No Poisons & $1.17375 \pm 0.000023$ & 1.17432 & 107 \\
\hline 2D & No Poisons & $1.16559 \pm 0.000023$ & 1.16584 & 75 \\
\hline 2E & 12 Pyrex & $1.06963 \pm 0.000024$ & 1.07164 & 233 \\
\hline 2F & 24 Pyrex & $0.97602 \pm 0.000026$ & 0.97855 & 232 \\
\hline 2G & 24 AIC & $0.84770 \pm 0.000025$ & 0.85253 & 227 \\
\hline 2H & 24 B4C & $0.78822 \pm 0.000025$ & 0.79289 & 40 \\
\hline 2I & Instrument Thimble & $1.17992 \pm 0.000024$ & 1.18077 & 221 \\
\hline 2J & Instrument +24 Pyrex & $0.97519 \pm 0.000025$ & 0.97780 & 240 \\
\hline 2K & Zoned + 24 Pyrex & $1.02006 \pm 0.000025$ & 1.02065 & 48 \\
\hline 2L & 80 IFBA & $1.01892 \pm 0.000024$ & 1.02013 & 239 \\
\hline 2M & 128 IFBA & $0.93880 \pm 0.000025$ & 0.94023 & 262 \\
\hline 2N & 104 IFBA + 20 WABA & $0.86962 \pm 0.000025$ & 0.87134 & 196 \\
\hline 2O & 12 Gadolinia & $1.04773 \pm 0.000024$ & 1.04967 & 174 \\
\hline 2P & 24 Gadolinia & $0.92741 \pm 0.000024$ & 0.93002 & 145 \\
\hline
\end{tabular}

In addition, Figure 5 shows a comparison of pin power distribution for KYLIN-V2.0 vs. KENO-VI for the 2D fuel lattices from the 2D HZP BOC fuel lattice problem. In particular, two representative parameters are chosen: " $\triangle \mathrm{P}$ RMS", that is the root mean square (RMS) of the power relative difference (KYLIN-V2.0 vs KENO-VI), and the maximum relative difference " $\triangle \mathrm{P}$ Max". It can be seen from Figure 5 that the maximum relative difference between the pin power calculated by KYLIN-V2.0 and the reference solution KENO-VI is within $0.6 \%$ except for case $2 \mathrm{O}, \Delta \mathrm{P}$ RMS is less than $0.3 \%$. Case $2 \mathrm{O}$ is a burnable poisons rod assembly containing $12 \mathrm{Gd} 2 \mathrm{O} 3$ rods. The comparison of pin power distributions for case $2 \mathrm{O}$ (KYLIN-V2.0 vs KENO-VI) are shown in Figure 6. Compared with the reference results, pin power relative difference of $1.24 \%$ appears where the relative pin-power is as low as 0.220 , where $\mathrm{Gd} 2 \mathrm{O} 3 \mathrm{rod}$ is placed. 


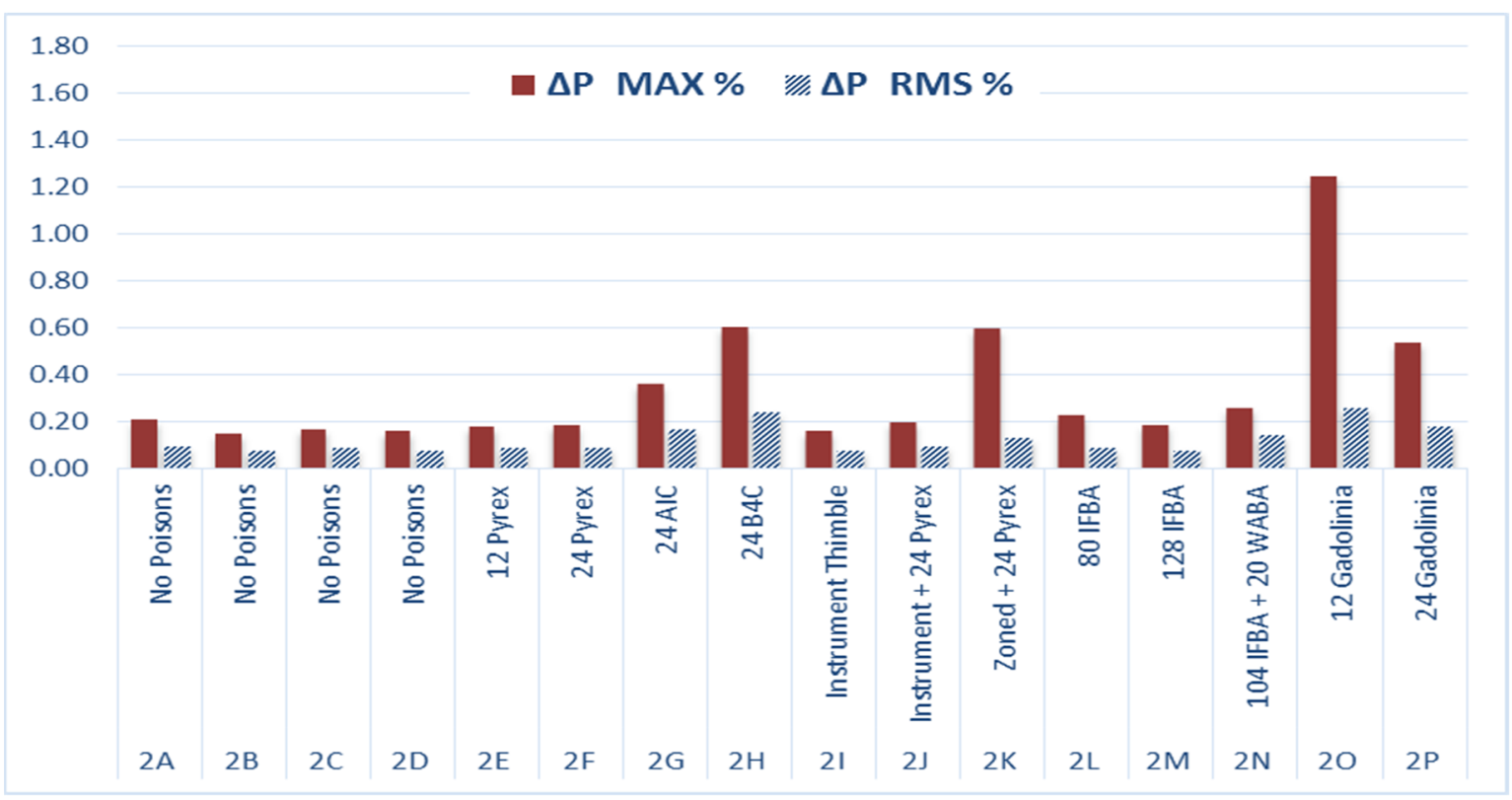

Figure 5. HZP $\triangle \mathrm{P}$ (RMS and Max) KYLIN-V2.0 vs KENO-VI for 2D lattice simulations.

\begin{tabular}{|c|c|c|c|c|c|c|c|c|}
\hline & & & & & & & \multirow{2}{*}{\multicolumn{2}{|c|}{$\begin{array}{c}\text { KENO-VI } \\
\text { KYLIN-V2.0 } \\
\text { Error }\end{array}$}} \\
\hline & & & & & & & & \\
\hline 1.105 & 1.071 & & & & & & & \\
\hline 1.103 & 1.070 & & & & & & & \\
\hline$-0.17 \%$ & $-0.09 \%$ & & & & & & & \\
\hline 1.089 & 1.050 & 1.018 & & & & & & \\
\hline 1.087 & 1.050 & 1.020 & & & & & & \\
\hline$-0.17 \%$ & $-0.02 \%$ & $0.20 \%$ & & & & & & \\
\hline & $\begin{array}{l}1.041 \\
1.039\end{array}$ & $\begin{array}{l}0.981 \\
0.980\end{array}$ & & & & & & \\
\hline & $-0.17 \%$ & $-0.05 \%$ & & & & & & \\
\hline 1.048 & 0.966 & 0.218 & 0.988 & 1.037 & & & & \\
\hline 1.048 & 0.966 & 0.219 & 0.988 & 1.039 & & & & \\
\hline $0.02 \%$ & $0.02 \%$ & $0.69 \%$ & $-0.02 \%$ & $0.22 \%$ & & & & \\
\hline 1.073 & 1.023 & 0.977 & 1.056 & 1.081 & & & & \\
\hline 1.072 & 1.021 & 0.978 & 1.054 & 1.082 & & & & \\
\hline$-0.06 \%$ & $-0.15 \%$ & $0.08 \%$ & $-0.14 \%$ & $0.07 \%$ & & & & \\
\hline & 1.093 & 1.082 & & 1.079 & 0.993 & 0.217 & & \\
\hline & 1.091 & 1.083 & & 1.081 & 0.994 & 0.220 & & \\
\hline & $-0.15 \%$ & $0.06 \%$ & & $0.20 \%$ & $0.09 \%$ & $1.24 \%$ & & \\
\hline 1.105 & 1.078 & 1.072 & 1.092 & 1.048 & 0.993 & 0.925 & 0.964 & \\
\hline 1.104 & 1.077 & 1.073 & 1.092 & 1.048 & 0.991 & 0.926 & 0.963 & \\
\hline$-0.12 \%$ & $-0.08 \%$ & $0.07 \%$ & $0.02 \%$ & $0.02 \%$ & $-0.21 \%$ & $0.06 \%$ & $-0.11 \%$ & \\
\hline 1.077 & 1.071 & 1.068 & 1.064 & 1.043 & 1.017 & 0.994 & 1.000 & 1.016 \\
\hline 1.076 & 1.071 & 1.067 & 1.063 & 1.043 & 1.016 & 0.995 & 1.000 & 1.017 \\
\hline$-0.10 \%$ & $-0.04 \%$ & $-0.07 \%$ & $-0.07 \%$ & $0.01 \%$ & $-0.08 \%$ & $0.15 \%$ & $0.04 \%$ & $0.06 \%$ \\
\hline
\end{tabular}

Figure 6. Pin power distribution of problem $2 \mathrm{O}$ fuel assembly for VERA benchmark.

\subsection{D 3x3 multi-assembly calculation}

The main objective of 2D $3 \times 3$ multi-assembly calculations was to verify that the agreement in effective multiplication factor and power distribution observed in 2D single-assembly calculations was maintained 
when considering the effect of neighboring assemblies. Three calculation cases have been performed by KYLIN-V2.0 for the 2D 3x3 multi-assembly, with results of keff, assembly power distributions and pin power distributions reported in Table IV. One calculation case without control rods ("uncontrolled"), one with AIC control rods inserted in the central lattice of the $3 \times 3$ and one with B4C control rods inserted in the central lattice. The ray option-3 polar and 16 azimuthal angles for each quadrant and $0.01 \mathrm{~cm}$ ray spacing - has been used, and the P1 calculation has been performed. The difference of keff between KYLIN-V2.0 and KENO-VI results for the three calculation problems are all within $300 \mathrm{pcm}$, consistent with the 2D single assembly results.

It can be seen from Table IV that the Max and RMS of assembly power relative difference are all less than $0.3 \%$, that are in better agreement with the reference. The pin power distribution comparison is slightly worse than for assembly power but still satisfactory, with pin RMS $<0.4 \%$ and Max $<2 \%$, which is caused by local power suppression in the control rod assembly and power redistribution to the other assemblies, especially the fuel lattice without control rods and Pyrex rods. And the pin power distribution can truly reflect the influence of local effect, while the assembly power reflects an average effect and cannot reflect the local effect. In addition, the KENO-VI pin power distribution and relative error of pin power between KYLIN-V2.0 and KENO-VI for 4C-2D multi-assembly problem is shown in Figure 7. It can be seen that pin power relative difference is less than $0.5 \%$ except for the very few rods of central control rod assembly, which is more than $1.0 \%$ and appears where the relative pin-power is as low as 0.48 , fuel rods near the center tube.

Table IV. Calculation result of 2D 3x3 multi-assembly.

\begin{tabular}{|c|c|c|c|c|c|c|c|}
\hline \multirow{2}{*}{ Case } & \multirow{2}{*}{ Description } & keff & $\Delta$ keff & \multicolumn{2}{c|}{ Assembly power diff } & \multicolumn{2}{c|}{ Pin power diff } \\
& & (KENO-VI) & {$[\mathrm{pcm}]$} & Max [\%] & RMS [\%] & Max [\%] & RMS [\%] \\
\hline 4A-2D & uncontrolled & 1.01024 & 242 & 0.16 & 0.12 & 0.88 & 0.28 \\
\hline 4B-2D & AIC Controlled & 0.98345 & 236 & 0.12 & 0.09 & 1.06 & 0.30 \\
\hline 4C-2D & B4C Controlled & 0.98029 & 225 & 0.27 & 0.16 & 1.70 & 0.33 \\
\hline
\end{tabular}

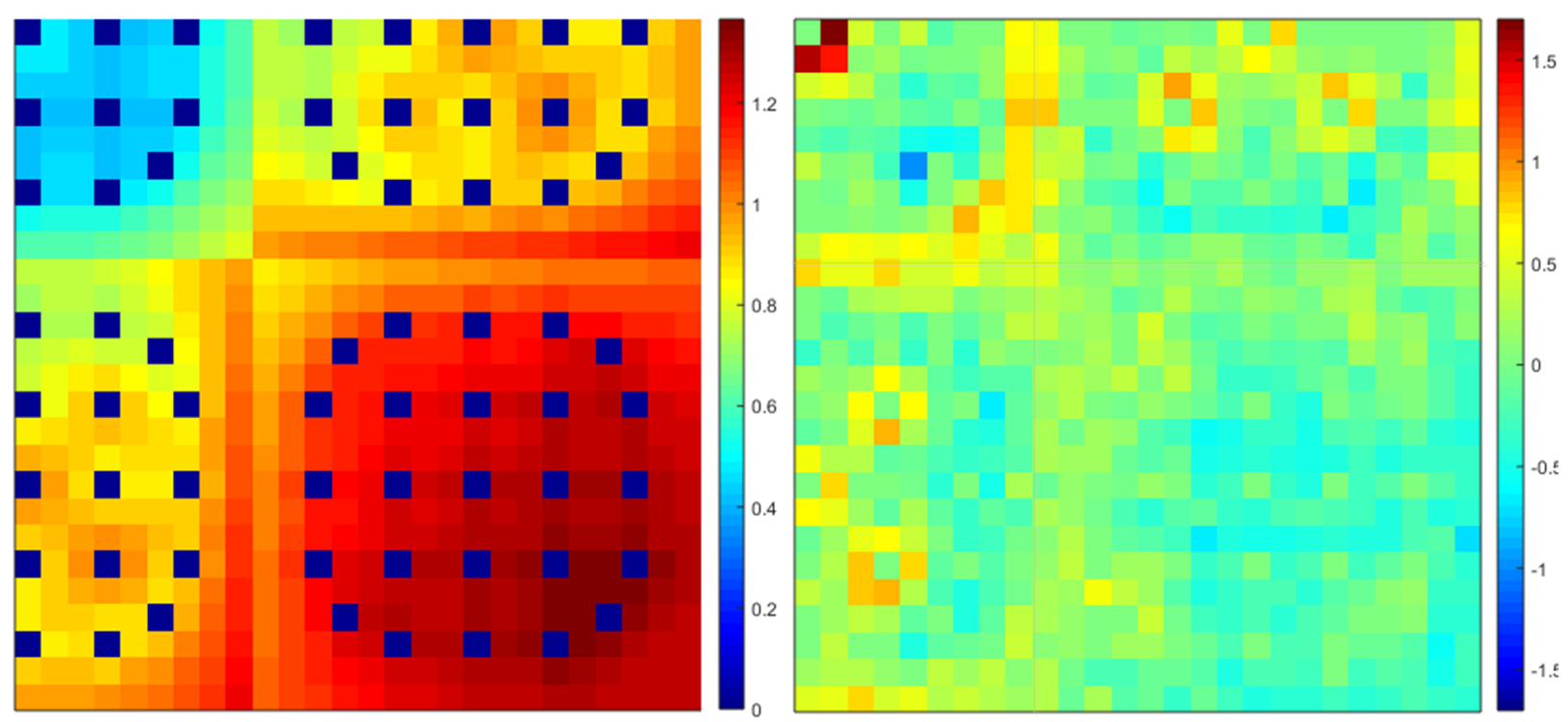

Figure 7. Pin power (KENO-VI, left) and relative error of pin power (KYLIN-V2.0 vs KENO-VI, right) for 4C-2D multi-assembly problem. 
In addition, rod reactivity worth have been calculated by KYLIN-V2.0 for the 4B-2D and 4C-2D. The results are shown in Table V. Good agreement can be found in those results, the relative errors are both less than $\pm 0.3 \%$ for the two calculation cases.

Table V. Calculation result of control rod reactivity worth.

\begin{tabular}{|c|c|c|c|c|}
\hline Case & Description & $\begin{array}{c}\text { Rod worth [pcm] } \\
\text { (KENO-VI) }\end{array}$ & $\begin{array}{c}\text { Rod worth [pcm] } \\
\text { (KYLIN-V2.0) }\end{array}$ & Relative error [\%] \\
\hline 4B-2D & AIC Controlled & $-2696 \pm 2$ & -2690 & -0.23 \\
\hline 4C-2D & B4C Controlled & $-3024 \pm 2$ & -3027 & 0.10 \\
\hline
\end{tabular}

\subsection{Assembly depletion}

The burnup calculation analysis of 2B fuel assembly in VERA benchmark has been performed by using KYLIN-V2.0. Since the depletion results of 2B fuel assembly are not given in the VERA benchmark, the results for this problem, calculated by a continuous energy (CE) Monte Carlo code named RMC, is chosen as the reference solution in this paper. For the assembly depletion problem, effective multiplication factor and pin power distributions at 0,30 and $60 \mathrm{GWd} / \mathrm{tU}$ comparisons are shown in Figure 8, Figure 9, Figure 10 and Figure 11 respectively. It can be seen from Figure 8 that the effective multiplication factor calculated by the two codes decreases continuously with the deepening of burnup, basically showing a linear law, that conforms to the burnup law of pure UO2 fuel. What's more, during the whole burnup process, the relative error of the effective multiplication factors between KYLIN-V2.0 and RMC remains within $\pm 0.3 \%$. In addition, it can be seen from Figure 9, Figure 10 and Figure 11 that the pin powers of 2B fuel assembly at different burnup calculated by KYLIN-V2.0 are in better agreement with the reference, and the maximum pin power error is only $-0.46 \%$, which appears near the water tunnel.

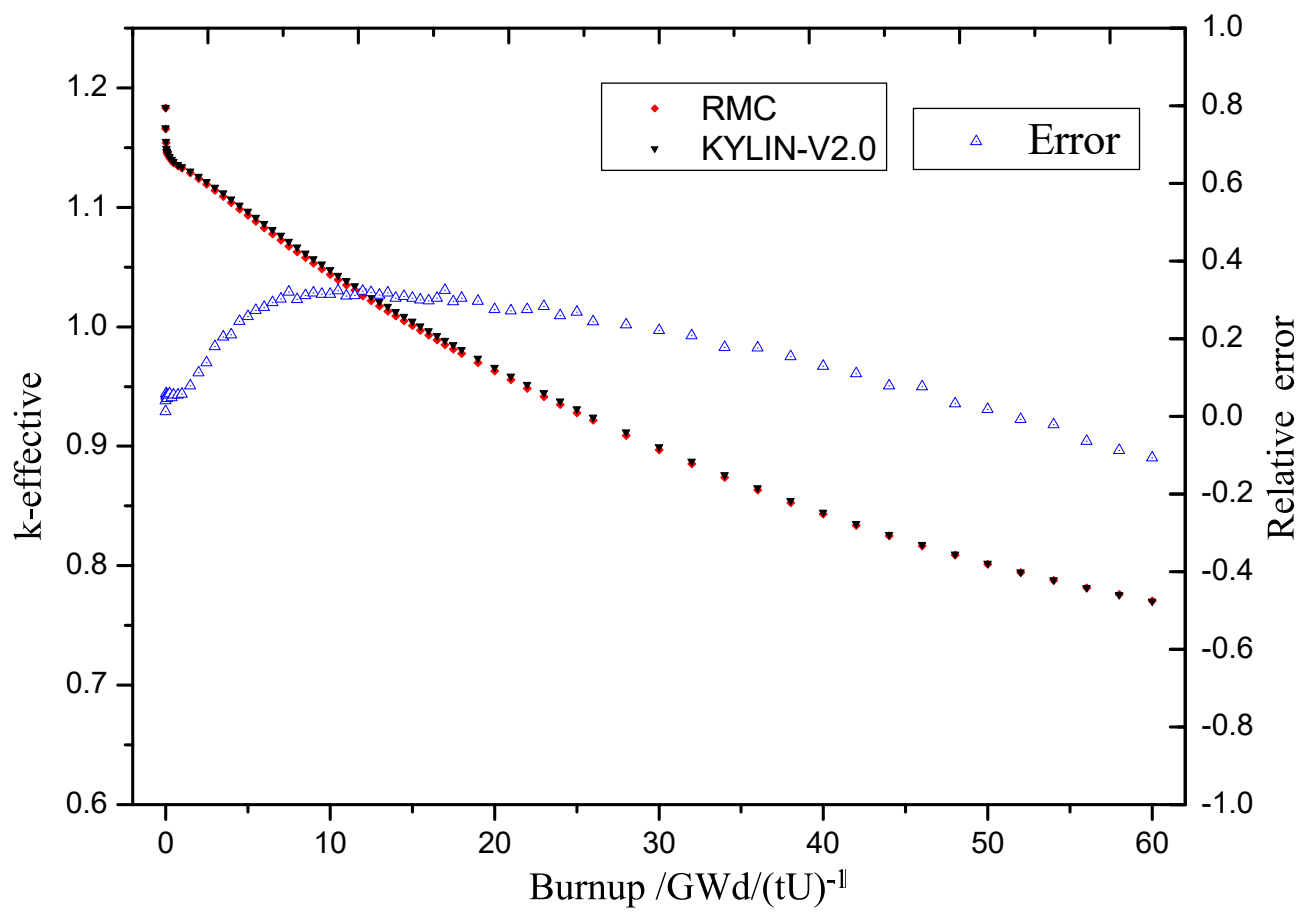

Figure 8. K-effective vs burnup for VERA 2B fuel assembly. 


\begin{tabular}{|c|c|c|c|c|c|c|c|c|}
\hline & & & & & & & \multirow{2}{*}{\multicolumn{2}{|c|}{$\begin{array}{c}\text { RMC } \\
\text { KYLIN-V2.0 } \\
\text { Error }\end{array}$}} \\
\hline & & & & & & & & \\
\hline 1.036 & 1.012 & & & & & & & \\
\hline 1.035 & 1.011 & & & & & & & \\
\hline$-0.14 \%$ & $-0.11 \%$ & & & & & & & \\
\hline 1.036 & 1.014 & 1.014 & & & & & & \\
\hline 1.035 & 1.011 & 1.012 & & & & & & \\
\hline$-0.12 \%$ & $-0.25 \%$ & $-0.16 \%$ & & & & & & \\
\hline & $\begin{array}{l}1.035 \\
1.035\end{array}$ & $\begin{array}{l}1.039 \\
1.037\end{array}$ & & & & & & \\
\hline & $0.03 \%$ & $-0.20 \%$ & & & & & & \\
\hline 1.033 & 1.011 & 1.016 & 1.043 & 1.029 & & & & \\
\hline 1.034 & 1.010 & 1.012 & 1.042 & 1.032 & & & & \\
\hline $0.12 \%$ & $-0.14 \%$ & $-0.40 \%$ & $-0.08 \%$ & $0.31 \%$ & & & & \\
\hline 1.032 & 1.003 & 1.010 & 1.043 & 1.047 & & & & \\
\hline 1.030 & 1.007 & 1.010 & 1.042 & 1.048 & & & & \\
\hline$-0.15 \%$ & $0.37 \%$ & $0.04 \%$ & $-0.09 \%$ & $0.06 \%$ & & & & \\
\hline & 1.024 & 1.027 & & 1.033 & 1.013 & 0.974 & & \\
\hline & 1.024 & 1.025 & & 1.034 & 1.015 & 0.975 & & \\
\hline & $-0.03 \%$ & $-0.18 \%$ & & $0.14 \%$ & $0.22 \%$ & $0.15 \%$ & & \\
\hline 1.009 & 0.990 & \begin{tabular}{|l|l}
0.989 \\
\end{tabular} & 1.009 & 0.983 & 0.965 & 0.948 & 0.940 & \\
\hline 1.011 & 0.990 & 0.989 & 1.010 & 0.984 & 0.966 & 0.950 & 0.941 & \\
\hline $0.16 \%$ & $0.04 \%$ & $0.03 \%$ & $0.12 \%$ & $0.14 \%$ & $0.10 \%$ & $0.18 \%$ & $0.06 \%$ & \\
\hline 0.980 & 0.974 & 0.974 & 0.975 & 0.966 & 0.956 & 0.947 & 0.941 & 0.946 \\
\hline 0.977 & 0.974 & 0.973 & 0.975 & 0.966 & 0.956 & 0.948 & 0.944 & 0.949 \\
\hline$-0.26 \%$ & $-0.01 \%$ & $-0.07 \%$ & $-0.05 \%$ & $0.04 \%$ & $-0.02 \%$ & $0.13 \%$ & $0.28 \%$ & $0.34 \%$ \\
\hline
\end{tabular}

Figure 9. VERA 2B fuel assembly pin power distribution at $0 \mathrm{GWd} / \mathrm{tU}$.

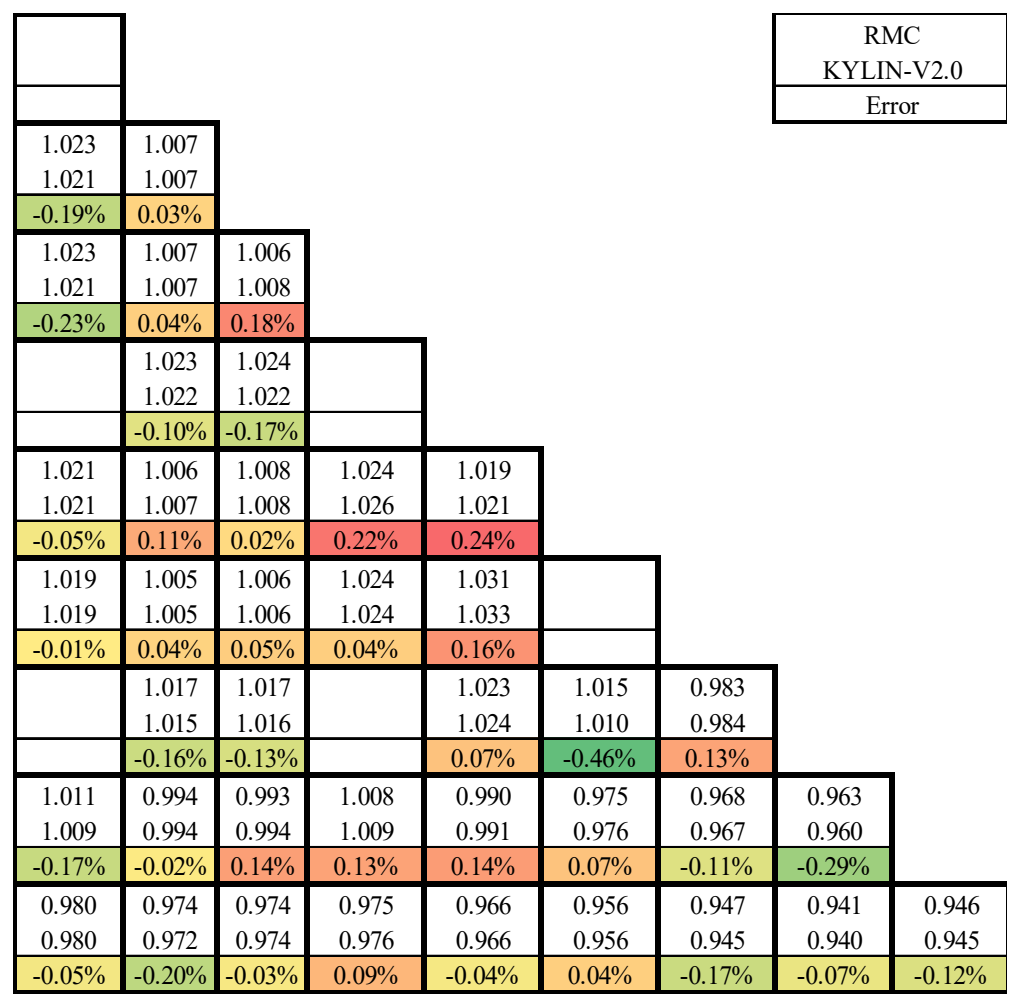

Figure 10. VERA 2B fuel assembly pin power distribution at $30 \mathrm{GWd} / \mathrm{tU}$. 


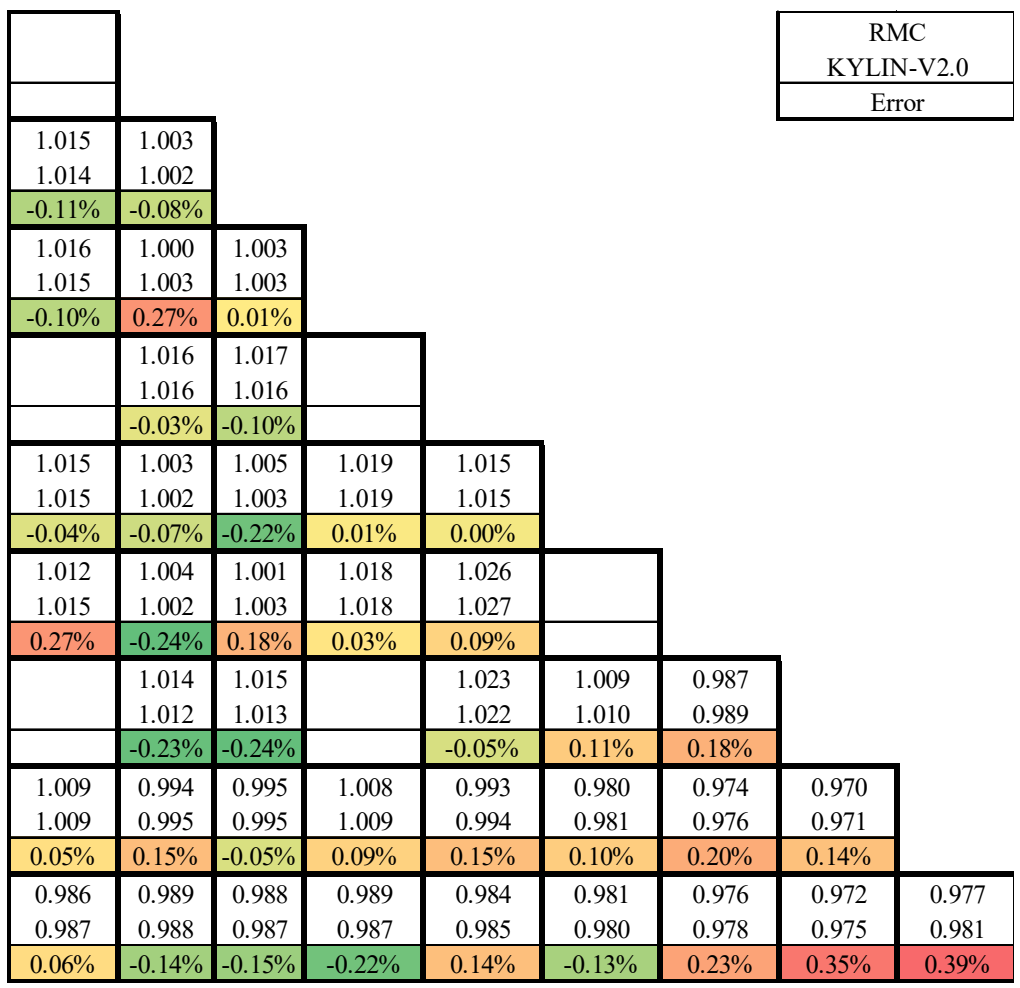

Figure 11. VERA 2B fuel assembly pin power distribution at $60 \mathrm{GWd} / \mathrm{tU}$.

\section{CONCLUSIONS}

In this paper, the calculation scheme and theoretical model in KYLIN-V2.0 code are briefly introduced. And in order to verify the calculation ability of KYLIN-V2.0 code, the effective multiplication factor, assembly power distribution, pin power distribution and control rod reactivity worth for various fuel assemblies in VERA benchmark are compared with Monte Carlo simulations from RMC code or the reference results from benchmark. The results prove that: 1) KYLIN-V2.0 code has the reliable capability of direct heterogeneous calculation of 2D fuel assembly; 2) KYLIN-V2.0 code can model these problems of the VERA benchmark very well, and can meet the requirements of calculation accuracy and function. Nevertheless, before it can be used in the design and analysis of advanced nuclear reactor, there is still more verification and validation work to be done.

\section{REFERENCES}

1. Tu X L, Chai X M, Lu W, et al. Development and V\&V of MOC module in advanced neutron transport lattice code KYLIN-V2.0[C]. 16th Academic Conference on Reactor Numerical Computing and Particle Transport and 2016 Reactor Physics Conference. Beijing, China 2016.

2. Chai X M, Tu X L, Guo F C, et al. Development and preliminary V\&V for advanced neutron transport lattice code KYLIN-V2.0[J]. High Power Laser and Particle Beams, 2017, 29(1): 1-7.

3. Nuclear Power Institute of China. Three-dimensional core neutron computation code CORCA-3D theory manual [R]. Nuclear Power Institute of China, 2016. 
4. Chai, X. M., Yao, D., and Wang, K., 2010, "Generalized Coarse-Mesh Finite Difference Acceleration for the Method of Characteristics," Advances in Reactor Physics to Power the Nuclear Renaissance (PHYSOR 2010), Pittsburgh, PA, May 9-14, American Nuclear Society, LaGrange Park, IL.

5. Isotalo AE, Wieselquist WA. A method for including external feed in depletion calculations with CRAM and implementation into ORIGEN[J]. Annals of Nuclear Energy, 2015, 85: 68-77.

6. Yamamoto A, Tatsumi M, Sugimura N. Projected Predictor-corrector Method for Lattice Physics Burnup Calculations[J]. Nuclear Science and Engineering, 2009, 163(2): 144-151.

7. Godfrey A. VERA Core Physics Benchmark Progression Problem Specifications, Revision 4[R]. Oak Ridge National Laboratory, 2012.

8. Wang K, Li Z G, She D, et al. RMC-A Monte Carlo code for reactor physics analysis[C]. Joint International Conference on Supercomputing in Nuclear Applications and Monte Carlo. Paris, France 2013. 